Article

\title{
Zn-Al Mixed Oxides Decorated with Potassium as Catalysts for HT-WGS: Preparation and Properties
}

\author{
Katarzyna Antoniak-Jurak*DD, Paweł Kowalik, Kamila Michalska, Wiesław Próchniak and \\ Robert Bicki
}

Łukasiewicz Research Network—New Chemical Syntheses Institute, Al. Tysiąclecia Państwa Polskiego 13A, 24-110 Puławy, Poland; pawel.kowalik@ins.lukasiewicz.gov.pl (P.K.);

kamila.michalska@ins.lukasiewicz.gov.pl (K.M.); wieslaw.prochniak@ins.lukasiewicz.gov.pl (W.P.);

robert.bicki@ins.lukasiewicz.gov.pl (R.B.)

* Correspondence: katarzyna.antoniak@ins.lukasiewicz.gov.pl; Tel.: +48-8-1473-1754

Received: 8 September 2020; Accepted: 18 September 2020; Published: 21 September 2020

\begin{abstract}
A set of ex-ZnAl-LDHs catalysts with a molar ratio of $\mathrm{Zn} / \mathrm{Al}$ in the range of $0.3-1.0$ was prepared using co-precipitation and thermal treatment. The samples were characterized using various methods, including X-ray fluorescence spectroscopy (XRF), X-ray photoelectron spectroscopy (XPS), X-ray powder diffraction (XRD), Fourier transform infrared spectroscopy FT-IR, $\mathrm{N}_{2}$ adsorption, Temperature-programmed desorption of $\mathrm{CO}_{2}\left(\mathrm{TPD}-\mathrm{CO}_{2}\right)$ as well as Scanning electron microscopy (SEM-EDS). Catalyst activity and long-term stability measurements were carried out in a high-temperature water-gas shift (HT-WGS) reaction. Mixed oxide catalysts with various Zn/Al molar ratios decorated with potassium showed high activity in the HT-WGS reaction within the temperature range of $330-400^{\circ} \mathrm{C}$. The highest activity was found for the $\mathrm{Zn} / \mathrm{Al}$ molar ratio of 0.5 corresponding to spinel stoichiometry. However, the catalyst with a stoichiometric spinel molar ratio of $\mathrm{Zn} / \mathrm{Al}$ (ZnAl_0.5_K) revealed a higher tendency for surface migration and/or vaporization of potassium during overheating at $450{ }^{\circ} \mathrm{C}$. The correlation of the activity results and TPD-CO 2 data show that medium basic sites enhance the progress of the HT-WGS reaction.
\end{abstract}

Keywords: layered double hydroxides; mixed oxides; spinel structure; potassium promoter; water gas shift

\section{Introduction}

The water-gas shift (WGS) reaction $\mathrm{CO}+\mathrm{H}_{2} \mathrm{O} \leftrightarrow \mathrm{CO}_{2}+\mathrm{H}_{2}\left(\Delta \mathrm{H}^{\circ}{ }_{298 \mathrm{~K}}=-41.1 \mathrm{~kJ} / \mathrm{mol}\right)$ is now, and will remain in the future, a very important method for the production of hydrogen [1,2]. The WGS reaction is also of great importance in the production of ammonia throughout steam reforming processes (expressed as $\mathrm{CH}_{4}+\mathrm{H}_{2} \mathrm{O} \leftrightarrow \mathrm{CO}+3 \mathrm{H}_{2}, \Delta \mathrm{H}^{\circ}{ }_{298 \mathrm{~K}}=205.8 \mathrm{~kJ} / \mathrm{mol}$ ) [3]. Usually, the WGS reaction is performed via a two-stage process to overcome thermodynamic and kinetic limitations [4]. The well-known Fe-Cr-Cu-based catalysts for HT-WGS have numerous significant disadvantages, including the presence of environmentally toxic $\mathrm{Cr}^{+6}$ with cancerogenic and mutagenic properties. Moreover, in the case of those catalysts, there is also the necessity of conducting the steam reforming process (preceding the HT-WGS process at syngas plants) at a $\mathrm{H}_{2} \mathrm{O} / \mathrm{C}$ ratio not lower than $\approx 2.8$ [5-7]. The decrease in this value, which is very favorable technologically, is connected with the risk of forming iron carbide-catalyzing side reactions (Fischer-Tropsch reactions), as the result of which hydrogen is consumed, causing a number of unfavorable consequences and leading to a decrease in process efficiency. Moreover, these systems are gradually deactivated by thermal recrystallization of $\mathrm{Fe}_{\mathrm{x}} \mathrm{O}_{\mathrm{y}}$ enhanced by steam [7]. The development of a new formula of HT-WGS catalyst without the above drawbacks, i.e., without the content of cancerogenic chromium and phyrophoric $\mathrm{Fe}_{\mathrm{x}} \mathrm{O}_{\mathrm{y}}$ and having 
both high and stable activity and resistance to coking or carbonation at a low steam/gas ratio, is an important area of investigation and long-standing interest for researchers $[8,9]$. Scientific contributions are mainly focused on the modification of iron-based formulas, i.e., non-stoichiometric magnetite $\mathrm{Fe}_{3-\mathrm{x}} \mathrm{O}_{4-y}$ doped with cerium, zirconium, aluminum, copper, and silica oxides [10-13].

Oxide systems $(\mathrm{Zn}-\mathrm{Al})$ of specific structures and properties can catalyze the WGS reaction and have many advantages compared to the conventional $\mathrm{Fe}-\mathrm{Cr}-\mathrm{Cu}$-based systems applied in the discussed reaction. Reviews of the literature indicate that catalysts prepared via hydrotalcite-like (layered double hydroxides-LDHs) precursor routes create particularly interesting opportunities [14-18]. The transition from layered double hydroxides (LDHs) to mixed metal oxides (MMOs) containing spinel oxides is a powerful approach to create materials with tailored properties suitable for various applications. Decomposition of $\mathrm{ZnAl}-\mathrm{LDHs}\left(>450^{\circ} \mathrm{C}\right)$ leads to the formation of nanocomposite systems of complex structures involving a metal oxide phase $\left(\mathrm{M}^{\mathrm{II}} \mathrm{O}\right)$, spinel-like phase $\left(\mathrm{M}^{\mathrm{II}} \mathrm{M}_{2}^{\mathrm{III}} \mathrm{O}_{4}\right.$ ), or systems containing both a spinel structure and single $\mathrm{ZnO}$ or $\mathrm{Al}_{2} \mathrm{O}_{3}$ (depending on the $\mathrm{Zn} / \mathrm{Al}$ molar ratio) with unique properties, i.e., highly developed specific surface area, homogeneous distribution of components (even on an atomic level) [19]. These features can make them attractive for numerous catalytic and photocatalytic applications [20,21]. Except from studies on the promoted nickel catalysts of the spinel structure $\mathrm{NiFe}_{2} \mathrm{O}_{4}[22,23]$ and other oxides of a spinel structure [24], literature dedicated to alternative systems based on metals other than $\mathrm{Fe}$ as an active agent is relatively sparse. The number of reports about applications of HT-WGS catalysts active $>300{ }^{\circ} \mathrm{C}$ based on simple or mixed oxides $\left(\mathrm{ZnO} / \mathrm{ZnAl}_{2} \mathrm{O}_{4}\right)$ is relatively low. To the best of our knowledge, the number of reports concerning the application of $\left(\mathrm{ZnO} / \mathrm{ZnAl}_{2} \mathrm{O}_{4}\right)$ catalysts is limited to a few references concerning the reverse water-gas shift $[25,26]$. Results of our studies conducted so far indicated that catalysts based on mixed oxides $\left(\mathrm{ZnO} / \mathrm{ZnAl}_{2} \mathrm{O}_{4}\right)$ promoted with alkali metals $(\mathrm{Na}, \mathrm{K}, \mathrm{Cs})$ may be considered as attractive alternative of conventional $\mathrm{Fe}-\mathrm{Cu}-\mathrm{Cr}$ applied in industrial practice. The catalytic properties of $\mathrm{K}$-promoted $\mathrm{ZnO} / \mathrm{ZnAl}_{2} \mathrm{O}_{4}$ and, especially, the effect of the $\mathrm{Zn} / \mathrm{Al}$ molar ratio on the efficiency and durability of WGS catalysts have not been studied so far.

The objective of this study is to explore the effect of disordered structure of $\mathrm{ZnAl}_{2} \mathrm{O}_{4}$ phase in $\mathrm{Zn} / \mathrm{Al}$ mixed oxide catalysts promoted with potassium on HT-WGS reaction. In particular, the effect of the $\mathrm{Zn} / \mathrm{Al}$ molar ratio on catalyst activity and thermal stability was investigated. Moreover, the effect of the $\mathrm{Zn} / \mathrm{Al}$ molar ratio on the structural, textural, and morphological properties of catalysts was investigated. The catalysts were characterized by a variety of techniques, including XRF, XPS, $\mathrm{XRD}, \mathrm{FT}-\mathrm{IR}, \mathrm{N}_{2}$ adsorption, TPD- $\mathrm{CO}_{2}$, and SEM-EDS. Catalytic activity and long-term stability in the HT-WGS reaction were determined in the kinetic regime at conditions similar to the industrial process.

\section{Results and Discussion}

The results of chemical analysis of the ZnAl_X_K (fresh) and ZnAl_X_K $\mathrm{K}_{\mathrm{AT}}$ (after long-term stability tests) catalysts are shown in Table 1. Additionally, in Table 1, the surface concentrations of potassium in the ZnAl_X_K catalysts, determined by XPS, have been presented. The atomic concentrations of potassium $\left(\mathrm{Ks}^{\mathrm{c}}\right)$ were converted into weight percentages to compare them with the values obtained from XRF and SEM-EDS analysis (Table 1). The XPS analysis of the fresh ZnAl_1.0_K catalyst confirmed a good agreement between the bulk and surface concentrations of potassium. As one can see from Table 1, the values of bulk and surface concentrations of potassium for ZnAl_0.3_K and ZnAl_0.5_K are not the same. In the case of the ZnAl_0.5_K catalyst, the surface concentration of $\mathrm{K}$ was higher than the bulk.

The XRF analysis of the ZnAl_X_K catalysts confirmed a good agreement between the real and nominal $\mathrm{Zn} / \mathrm{Al}$ molar ratios. In addition, Table 1 shows the composition of potassium $\left(\mathrm{K}^{\mathrm{a}}\right)$ determined by SEM-EDS for the fresh catalysts (ZnAl_X_K) and for the catalysts after long-term stability tests $\left(\mathrm{ZnAl} \_\mathrm{X} \_\mathrm{K}_{\mathrm{AT}}\right)$. For both series, a good agreement between the bulk $\left(\mathrm{K}^{\mathrm{b}}\right.$-determined by $\left.\mathrm{XRF}\right)$ and the content of potassium determined by SEM-EDS $\left(\mathrm{K}^{\mathrm{a}}\right)$ was confirmed. 
Table 1. The chemical compositions and textural properties of the ZnAl_X_K and ZnAl_X_K AT catalysts with different $\mathrm{Zn} / \mathrm{Al}$ molar ratios.

\begin{tabular}{|c|c|c|c|c|c|c|c|}
\hline Sample & $(\mathrm{Zn} / \mathrm{Al})_{\mathrm{mol}}$ & [wt. \%] $\mathrm{K}^{\mathrm{a}}$ & [wt. \%] $\mathbf{K}^{\mathbf{b}}$ & $\begin{array}{c}\text { [wt. \%] } \\
\text { Ks s}^{c}\end{array}$ & $\begin{array}{c}\mathrm{S}_{\mathrm{BET}} \\
{\left[\mathrm{m}^{2} / \mathrm{g}\right]}\end{array}$ & $\begin{array}{c}V c \\
{\left[\mathrm{~cm}^{3} / \mathrm{g}\right]^{\mathrm{e}}}\end{array}$ & $\underset{\left[\mathrm{cm}^{3} / \mathrm{g}\right]^{\mathrm{f}}}{\mathrm{fm}}$ \\
\hline ZnAl_0.3_K & 0.29 & 3.1 & 3.1 & 2.4 & 154 & 0.53 & 0.48 \\
\hline $\mathrm{ZnAl}$-0.3_K $\mathrm{AT}$ & 0.27 & 2.8 & 2.7 & - & 126 & 0.38 & 0.32 \\
\hline ZnAl_0.5_K & 0.52 & 2.6 & 2.6 & 3.5 & 100 & 0.43 & 0.31 \\
\hline ZnAl_0.5_K $\mathrm{K}_{\mathrm{AT}}$ & 0.46 & 2.1 & 2.1 & - & 77 & 0.34 & 0.25 \\
\hline ZnAl_1.0_K & 0.95 & 2.9 & 2.8 & 2.7 & 77 & 0.37 & 0.18 \\
\hline ZnAl_1.0_K $\mathrm{K}_{\mathrm{AT}}$ & 0.92 & 2.6 & 2.6 & - & 41 & 0.13 & 0.08 \\
\hline
\end{tabular}

${ }^{a}$ determined by SEM-EDS; ${ }^{b}$ determined by XRF; ${ }^{c}$ determined by XPS; ${ }^{d}$ total internal surface area determined by Brunauer-Emmett-Teller; ${ }^{\mathrm{e}}$ total pore volume determined by the Barret-Joyner-Halend method; ${ }^{\mathrm{f}}$ mesopores volume determined by the Barret-Joyner-Halend method.

For the catalysts with a non-stoichiometric $\mathrm{Zn} / \mathrm{Al}$ molar ratio $\left(\mathrm{ZnAl} \_0.3 \_\mathrm{K}_{\mathrm{AT}}\right.$ and $\left.\mathrm{ZnAl} \_1.0 \_\mathrm{K}_{\mathrm{AT}}\right)$, after thermal stability tests, slight differences in potassium content were observed. However, they were more significant for the sample of $\mathrm{ZnAl}$ _0.5_K $\mathrm{K}_{\mathrm{AT}}$. It seems that this can be associated with the higher tendency for surface migration and/or vaporization of potassium during overheating at $450{ }^{\circ} \mathrm{C}$. Comparing the total content of potassium in the $\mathrm{ZnAl}$ X_K $\mathrm{K}_{\mathrm{AT}}$ series catalysts, determined by the XRF technique, with composition determined by SEM-EDS, it can be concluded that during long-term stability tests, potassium was just slightly evaporated. Similar conclusions come from the work of Bieniasz et al. [27]. According to the authors of this work, alkali promoters may agglomerate or be removed from the catalyst surface due to their volatility at higher temperatures. Moreover, the onset of potassium desorption was observed at $400{ }^{\circ} \mathrm{C}$, meaning that during the HT-WGS process at temperatures below $400{ }^{\circ} \mathrm{C}$, potassium does not escape from the surface of catalyst. When the HT-WGS process was carried out above $400^{\circ} \mathrm{C}$, potassium became mobile.

The comparison of diffraction patterns for ZnAl_X_LDHs precursors with different molar ratio of $\mathrm{Zn} / \mathrm{Al}$ is presented in Figure 1A,B, respectively. As shown in Figure 1A, the presence of characteristics for the LDH-phase peaks is observed. In the set of diffraction patterns, the first band (in the range $2 \theta$ : $\left.11-12^{\circ}\right)$ is the strongest reflex coming from the hydrotalcite-like $\mathrm{LDH}$ of the formula $\mathrm{Zn}_{0.63} \mathrm{Al}_{0.37}(\mathrm{OH})_{2}$ $\left(\mathrm{CO}_{3}\right)_{0.185^{\circ}} \times \mathrm{xH}_{2} \mathrm{O}$. However, the intensity of the characteristics bands at angle $2 \theta: 11.79^{\circ}(003), 23.69^{\circ}(006)$, $34.78^{\circ}(012), 39.47^{\circ}(015), 44.27^{\circ}(018), 60.50^{\circ}$ (110) $61.88^{\circ}$ (113) decreased with the decreased in $\mathrm{Zn} / \mathrm{Al}$ molar ratio. In the case of the ZnAl_0.3 material, XRD patterns indicated the presence of a poorly crystallized ZnAl-LDHs phase (Figure 1B). Moreover, it was shown that with the increase in the $\mathrm{Zn} / \mathrm{Al}$ molar ratio in precursors, the parameter " $\mathrm{c}$ " decreased and, at the same time, the parameter "LDH interlamellar distance" increased (see Table S1).

The diffraction patterns for the ZnAl_X_K catalysts are presented in Figure 2. In the diffractograms of $\mathrm{ZnAl}$-0.3_K and $\mathrm{ZnAl} \_0.5 \_\mathrm{K}$, the characteristic bands for the cubic spinel structure $\mathrm{ZnAl}_{2} \mathrm{O}_{4}$ with relatively high crystallinity were evidenced at $2 \theta: 31.26^{\circ}(220), 36.68^{\circ}(311), 44.87^{\circ}(400)$, (311), $55.85^{\circ}(422), 59.35^{\circ}(511)$, and $65.35^{\circ}(440)[28,29]$. Due to the structural similarity and similar diffraction images, it is justified to assign reflections for $2 \theta: 31.80^{\circ}, 36.10^{\circ}$, and $56.56^{\circ}$ corresponding to diffraction on planes (100), (101), and (110), respectively, to the crystalline phase of wurtzite ( $\mathrm{ZnO}$ ) [30]. 

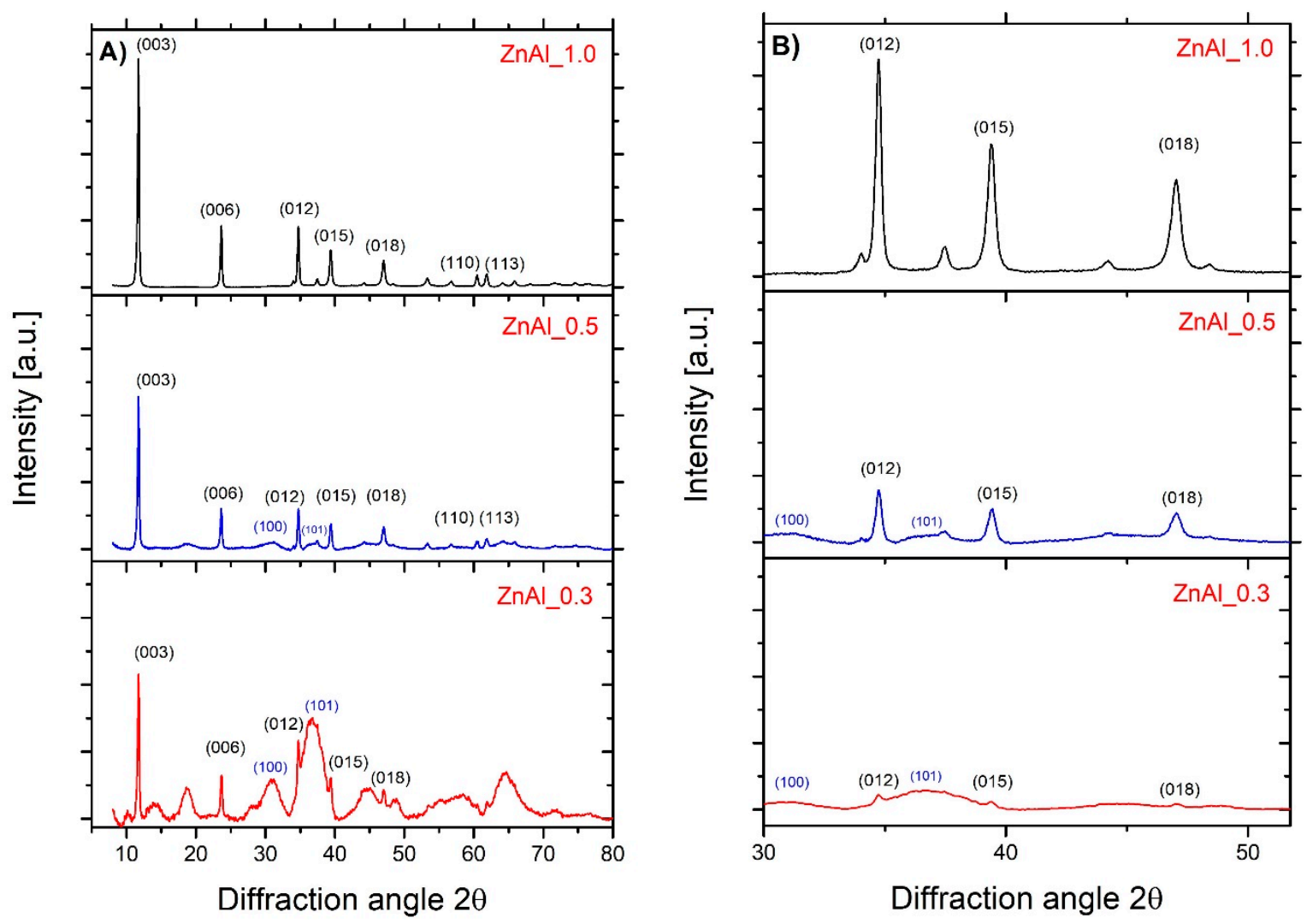

Figure 1. (A) XRD patterns of $\mathrm{ZnAl}-\mathrm{LDH}$ with different $\mathrm{Zn} / \mathrm{Al}$ molar ratios; $\mathrm{Zn}_{0.63} \mathrm{Al}_{0.37}(\mathrm{OH})_{2}$ $\left(\mathrm{CO}_{3}\right)_{0.185} \times \mathrm{xH}_{2} \mathrm{O}$ phase bands at $2 \theta: 11.79^{\circ}(003), 23.69^{\circ}(006), 34.78^{\circ}(012), 39.47^{\circ}(015), 44.27^{\circ}(018)$, $60.50^{\circ}(110)$, and $61.88^{\circ}$ (113); $\mathrm{ZnO}$ phase peaks at angles $2 \theta: 31.8^{\circ}$ (100) $36.1^{\circ}$ (101). (B) XRD patterns of $\mathrm{ZnAl}-\mathrm{LDH}$ with different $\mathrm{Zn} / \mathrm{Al}$ molar ratios at $2 \theta$ from 30 to $55^{\circ}$.

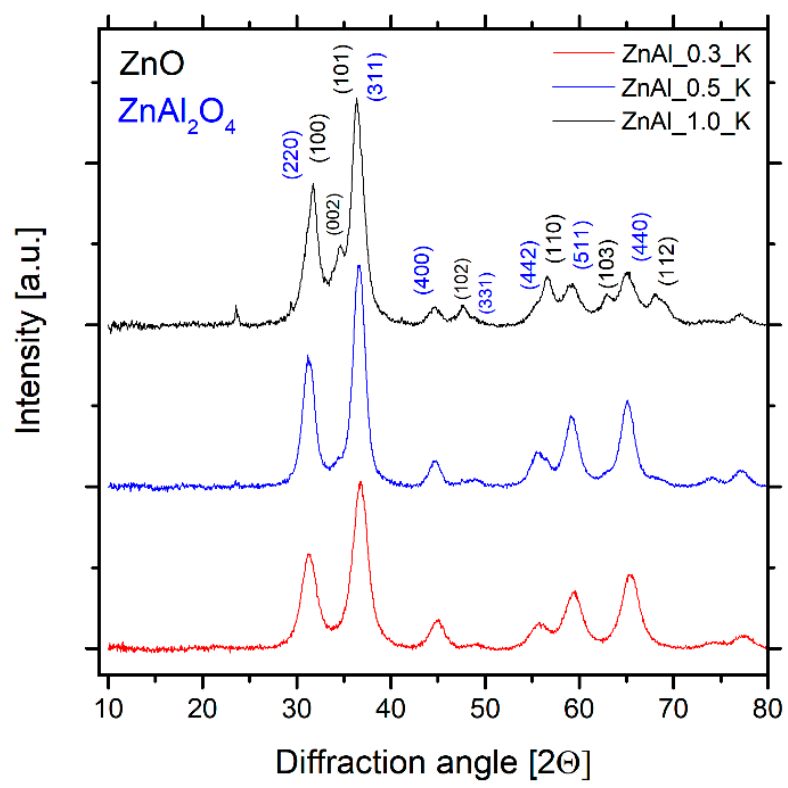

Figure 2. XRD patterns of fresh ZnAl_X_K catalysts.

For the ZnAl_1.0_K sample, spinel phase $\mathrm{ZnAl}_{2} \mathrm{O}_{4}$ at $2 \theta: 31.28^{\circ}(220), 36.93^{\circ}(311), 44.62^{\circ}(400)$, $55.30^{\circ}(422), 59.14^{\circ}(511)$, and $65.01^{\circ}(440)$ was detected. It is worth noticing that for higher molar ratios of Zn/Al (ZnAl_1.0_K), the appearance of an additional phase for angles $2 \theta: 34.63^{\circ}, 47.60^{\circ}, 56.57^{\circ}$, 
$62.95^{\circ}$ and $68.05^{\circ}$, corresponding to diffraction on planes (002), (102), (110), (103), and (112), respectively, characteristic of a $\mathrm{ZnO}$ phase, is visible. It appears that residual zinc oxide which was not incorporated into the spinel structure is present as an individual phase. No phases originating from potassium compounds for the $\mathrm{ZnAl} \_0.3 \_\mathrm{K}$ and $\mathrm{ZnAl} 0.5 \_\mathrm{K}$ samples were evidenced on the XRD patterns. In the case of the ZnAl_1.0_K sample, potassium was evidenced as $\mathrm{KNO}_{3}$ which was demonstrated by the appearance of weak reflections for angles $2 \theta: 22.90^{\circ}$ and $29.55^{\circ}$. These observations were confirmed by further FT-IR measurements.

The FT-IR spectra of ZnAl-LDHs with variable $\mathrm{Zn} / \mathrm{Al}$ molar ratios are presented in Figure 3. In all of the samples, three major regions of bands were identified for wavenumbers: $400-800 \mathrm{~cm}^{-1}, 1550-1250$ $\mathrm{cm}^{-1}$, and 3750-2500 $\mathrm{cm}^{-1}$. In the FT-IR spectra, for wavenumbers $3750-2500 \mathrm{~cm}^{-1}$, wide bands with a similar intensity, which are characteristic of stretching bands of $\mathrm{O}-\mathrm{H}$ in water particles present in interlayer spaces of LDHs and in brucite-like layers, were identified. Moreover, with the increase in the molar ratio of $\mathrm{Zn} / \mathrm{Al}$, a shift of bands towards higher wavenumbers (ZnAl_1.0, maximum $3354 \mathrm{~cm}^{-1}$ ) was observed.

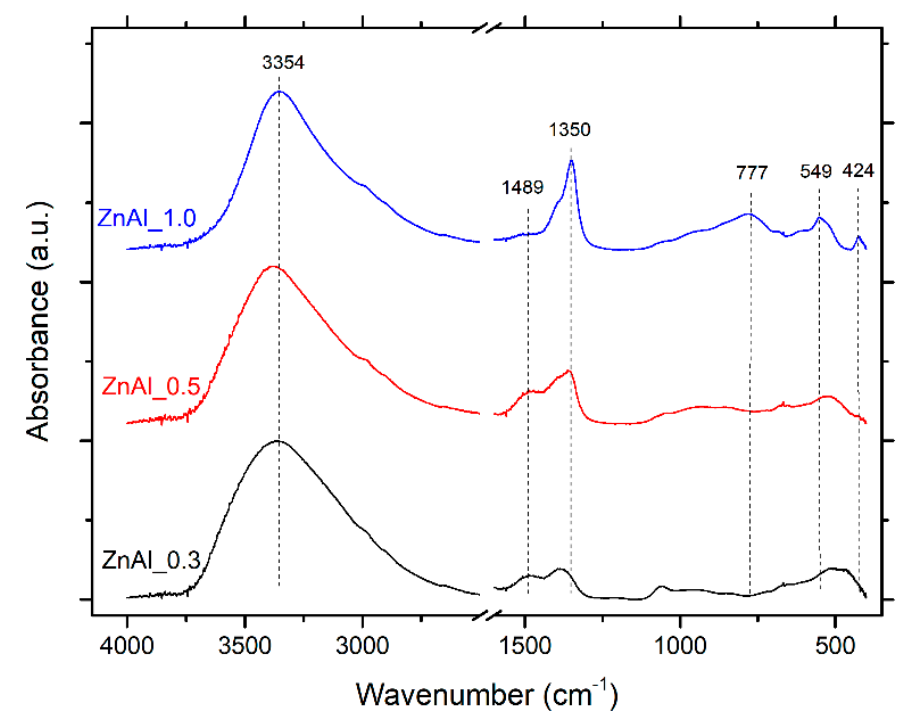

Figure 3. FT-IR spectra of ZnAl-LDHs_X samples with different $\mathrm{Zn} / \mathrm{Al}$ molar ratio.

For wavenumbers $1550-1300 \mathrm{~cm}^{-1}$, bands characteristic of antisymmetric stretching vibrations of $\mathrm{CO}_{3}{ }^{2-}$ present for interlayer spaces of $\mathrm{LDHs}$ were visible. The intensity of these bands changed with the increase in the $\mathrm{Zn} / \mathrm{Al}$ molar ratio, with the band of the highest intensity (maximum 1350 $\mathrm{cm}^{-1}$ ) at $\mathrm{ZnAl}$ 1.0. The contribution of $\mathrm{CO}_{2}$ in LHDs is in agreement with the data presented in Table S1. For wavenumbers $400-800 \mathrm{~cm}^{-1}$, band characteristics of stretching modes of metal-oxygen-metal bonds, i.e., (Al-O-Al) and $(\mathrm{Zn}-\mathrm{O}-\mathrm{Zn})$, were present. The most characteristic band differentiating ZnAl_LDHs samples was the band at wavenumbers $700-800 \mathrm{~cm}^{-1}$, present only for ZnAl_1.0_K (maximum $777 \mathrm{~cm}^{-1}$ ).

This indicates the presence of bending vibrations of $\mathrm{O}-\mathrm{H}$ groups of $\mathrm{H}_{2} \mathrm{O}$ as well as $\mathrm{Al}-\mathrm{O}-\mathrm{Al}$ and $\mathrm{Zn}-\mathrm{O}-\mathrm{H}$ chemical bonds.

In Figure 4, the FT-IR spectra of ZnAl_X_K are presented. For the set of ZnAl_X_K catalysts, four major regions for wavenumbers were evidenced: $400-700 \mathrm{~cm}^{-1}, 700-850 \mathrm{~cm}^{-1}, 1550-1250 \mathrm{~cm}^{-1}$, and $3750-2500 \mathrm{~cm}^{-1}$. In the case of the $\mathrm{ZnAl} \_\mathrm{X} \_\mathrm{K}$ samples (re-calcined at $450{ }^{\circ} \mathrm{C}$ after impregnation with aqueous solution of potassium nitrate), wide bands at wavenumbers in the range of $3750-2500 \mathrm{~cm}^{-1}$ corresponding to the stretching of $\mathrm{O}-\mathrm{H}$ bonds are visible in FT-IR spectra. These bands are characteristic of water intercalated between the layers of the rehydrated ex-hydrotalcite-like mixed $\mathrm{Zn}-\mathrm{Al}$ oxides. Moreover, with the increase of the $\mathrm{Zn} / \mathrm{Al}$ molar ratio, the shift of bands towards higher wavenumbers (ZnAl_1.0, maximum $3420 \mathrm{~cm}^{-1}$ ) was observed. For wavenumbers of $1550-1400 \mathrm{~cm}^{-1}$, 
bands characteristic of stretching vibrations of $\mathrm{CO}_{3}{ }^{2-}$ intercalated between the layers of the rehydrated ex-hydrotalcite-like mixed $\mathrm{Zn}-\mathrm{Al}$ oxides were evidenced. The $\mathrm{CO}_{3}{ }^{2-}$ stretching vibration became weaker with a slight shift to a higher frequency on decreasing the $\mathrm{Zn} / \mathrm{Al}$ molar ratio, although it was still indicative of the $\mathrm{CO}_{3}{ }^{2-}$ groups' decomposition and subsequent $\mathrm{CO}_{2}$ removal from the interlayer space. Additionally, in the ZnAl_1.0_K sample, at 2922 and $2900 \mathrm{~cm}^{-1}$, bands characteristic of stretching vibrations of $\mathrm{CO}_{3}^{2}$ were detected. In addition, the FT-IR results showed bands of high intensity at $1374-1378 \mathrm{~cm}^{-1}$ owing to stretching vibrations of $\mathrm{CO}_{3}{ }^{2-}$ intercalated between the layers of reconstructed ex-hydrotalcite-like mixed $\mathrm{Zn}-\mathrm{Al}$ oxides.
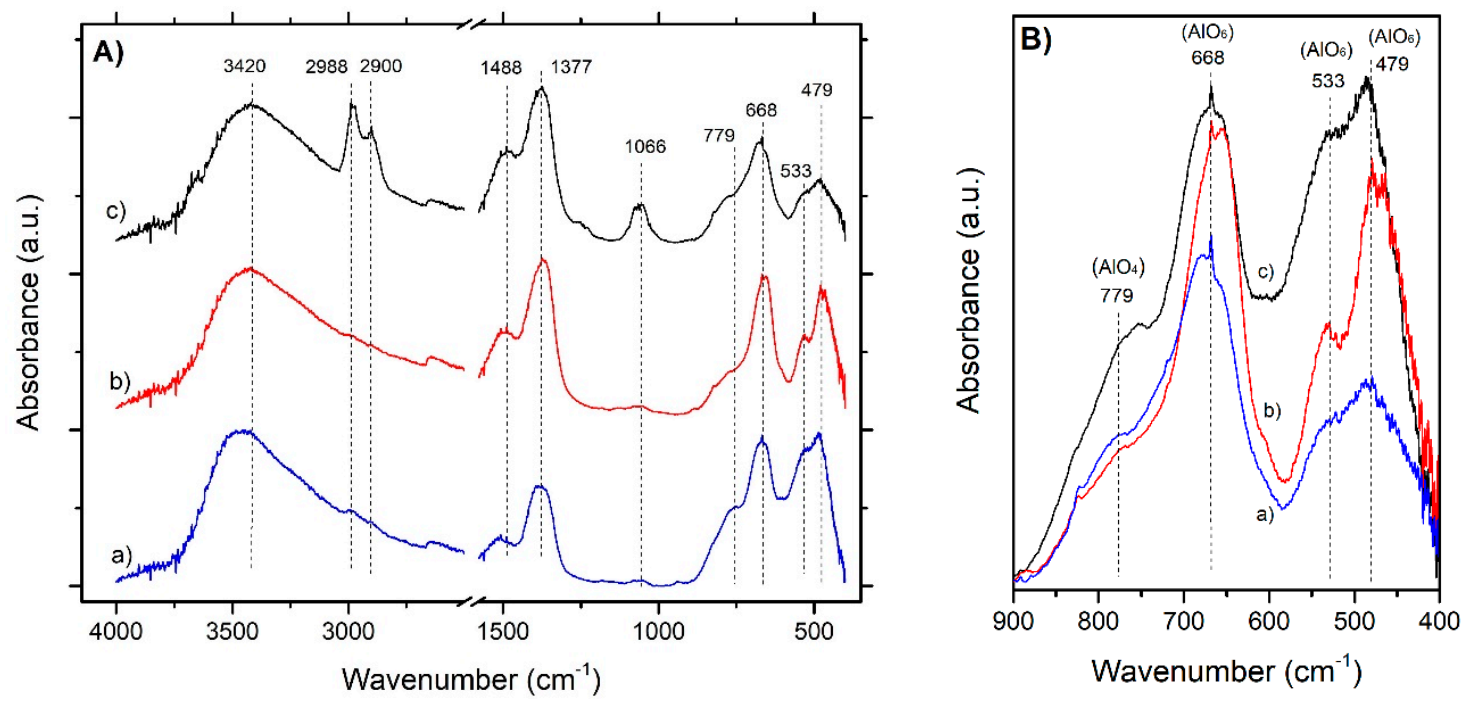

Figure 4. (A) FT-IR spectra of $\mathrm{ZnAl} \_X \_K$ catalysts with different $\mathrm{Zn} / \mathrm{Al}$ molar ratios. (a) ZnAl_0.3_K, (b) ZnAl_0.5_K, (c) ZnAl_1.0_K. (B) The presence of bands characteristic of tetrahedral aluminum $\left(\mathrm{AlO}_{4}\right)$ and octahedral aluminum $\left(\mathrm{AlO}_{6}\right)$.

Moreover, for the ZnAl_1.0_K sample, a single peak centered at $1066 \mathrm{~cm}^{-1}$ is attributed to $\mathrm{NO}_{3}{ }^{-}$ anions. For wavenumbers $700-400 \mathrm{~cm}^{-1}$, bands characteristic of stretching and bending vibrations of the $\mathrm{Al}-\mathrm{O}$ bond with octahedral coordination $\left(\mathrm{AlO}_{6}\right)$ were visible. Bands at $688 \mathrm{~cm}^{-1}$ and $533 \mathrm{~cm}^{-1}$ corresponded to stretching vibrations of Al-O, whereas the band at $479 \mathrm{~cm}^{-1}$ could be attributed to bending $\mathrm{O}-\mathrm{Al}-\mathrm{O}$ bonds with octahedral coordination $\left(\mathrm{AlO}_{6}\right)$. However, with the increase in the $\mathrm{Zn} / \mathrm{Al}$ molar ratio, a decrease in the relative intensity of these bands was observed. Moreover, for ZnAl_0.3_K and $\mathrm{ZnAl} \_0.5 \_\mathrm{K}$, bands with a low intensity, in the range of wavenumbers $700-850 \mathrm{~cm}^{-1}$, coming from $\mathrm{Al}-\mathrm{O}$ bonds with tetrahedral coordination $\left(\mathrm{AlO}_{4}\right)$, were identified. The presence of these bonds indicates that the spinel formed under the applied conditions is a zinc-deficient spinel. According to the literature, preparation via coprecipitation and moderate calcinations $\left(<600^{\circ} \mathrm{C}\right)$ of mixed oxides (also with a stoichiometric spinel molar ratio of $\mathrm{Zn} / \mathrm{Al}$ ) usually leads to zinc-deficient spinel [19-21]. In the ZnAl_1.0_K sample, the intensity of the bands attributed to tetrahedral aluminum $\left(\mathrm{AlO}_{4}\right)$ was higher. The presence of bands characteristic of tetrahedral aluminum $\left(\mathrm{AlO}_{4}\right)$ indicates the partial inversion of the $\mathrm{ZnAl}_{2} \mathrm{O}_{4}$ spinel structure.

Figure 5 shows $\mathrm{N}_{2}$ adsorption-desorption isotherms of the $\mathrm{ZnAl} \mathrm{X} \_\mathrm{K}$ and $\mathrm{ZnAl} \_\mathrm{X} \_\mathrm{K}_{\mathrm{AT}}$ samples with different $\mathrm{Zn} / \mathrm{Al}$ molar ratios. All of the isotherms correspond to H3-type hysteresis according to IUPAC [31], which is a characteristic feature of mesoporous solids. The specific surface area and porous structure parameters of the $\mathrm{ZnAl} \_\mathrm{X} \_\mathrm{K}$ and $\mathrm{ZnAl} \_\mathrm{X} \_\mathrm{K}_{\mathrm{AT}}$ catalysts are given in Table 1 . These results show that specific surface areas of the fresh ZnAl_X_K catalysts were in the range of $77-154 \mathrm{~m}^{2} / \mathrm{g}$. With increased $\mathrm{Zn} / \mathrm{Al}$ molar ratios, significantly lower specific surface areas with a concomitant lower pore volume were observed. A radically lower value of specific surface area (at about 50\%) was determined for ZnAl_1.0_K compared to the ZnAl_0.3_K sample. For the ZnAl_X_K 
a significant decrease in the specific surface area was observed (by $20 \%$ as compared to the fresh samples) due to the progressing, sintering, and concomitant pore collapsing. Recrystallization processes were clearly visible for $\mathrm{ZnAl} \_1.0 \_K$, the evidence of which is a decrease in $\mathrm{S}_{\mathrm{BET}}$ by $40 \%$ and in total pore volume $\left(\mathrm{V}_{\mathrm{c}}\right)$ by over $60 \%$ as compared to fresh sample. The materials of the $\mathrm{ZnAl}$ X__ $\mathrm{K}_{\mathrm{AT}}$ series are characteristic of a lower total pore volume as compared to ZnAl_X_K ones.
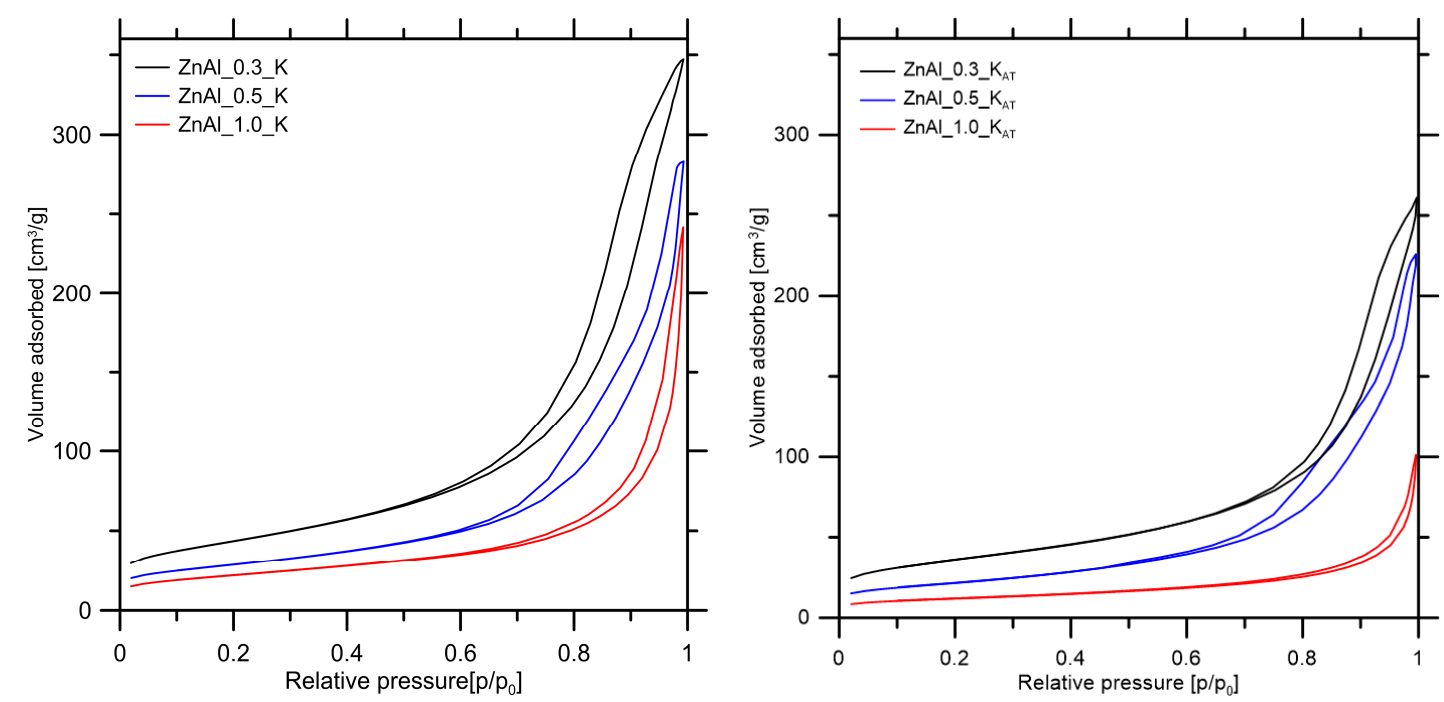

Figure 5. $\mathrm{N}_{2}$ adsorption-desorption isotherm of $\mathrm{ZnAl} \_\mathrm{X} \_\mathrm{K}$ and $\mathrm{ZnAl} \mathrm{X} \_\mathrm{K}_{\mathrm{AT}}$ catalysts with different $\mathrm{Zn} / \mathrm{Al}$ molar ratios.

Figure S1 shows the pore size distribution of the ZnAl_X_K and ZnAl_X_K $\mathrm{K}_{\mathrm{AT}}$ samples with different $\mathrm{Zn} / \mathrm{Al}$ molar ratios.

Pore size distributions prove that pores with a diameter of 20-60 nm account for the majority of the porous structure of the obtained materials. The porous structure comprises three types of pores: mesopores with diameter ranging from 2 to $10 \mathrm{~nm}$, wide mesopores with a dominant diameter of $20-50 \mathrm{~nm}$, and macropores with a dominant diameter of 140-150 nm. The materials of the $\mathrm{ZnAl}$ _X_K $\mathrm{K}_{\mathrm{AT}}$ series are characteristic of lower total pore volume as compared to materials of the ZnAl_X_K series and the dominant pore diameter increased due to overheating.

The surface morphology of the $\mathrm{ZnAl} \_\mathrm{X} \_\mathrm{K}$ series (fresh catalysts with different $\mathrm{Zn} / \mathrm{Al}$ molar ratios) were examined by SEM (Figure 6). Figure 6A,B show that the ZnAl_0.3_K and ZnAl_0.5_K catalysts are built with tightly connected rough quasi-spherical particles and, thus, the hexagonal plate-like morphology typical for LDH materials was not detected. It evidences that the lamellar structure of LDHs was destroyed during thermal treatment. The morphology of the fresh ZnAl_1.0_K catalyst was significantly different (Figure 6C,D). The ZnAl_1.0_K catalyst exhibited a hexagonal platelet morphology of randomly oriented grains. Moreover, aggregates composed of round-edged nanoparticles on their surfaces were also present. It can be seen that, for higher $\mathrm{Zn} / \mathrm{Al}$ molar ratios, the platelet-like morphology was not totally transformed into a spherical one. However, during the thermal stability test of the $\mathrm{ZnAl} 1$ 1.0_K $\mathrm{K}_{\mathrm{AT}}$ catalyst, the hexagonal plates became aggregated and the presence of larger particles with rounded edges is evidenced on SEM images (Figure 6E). 

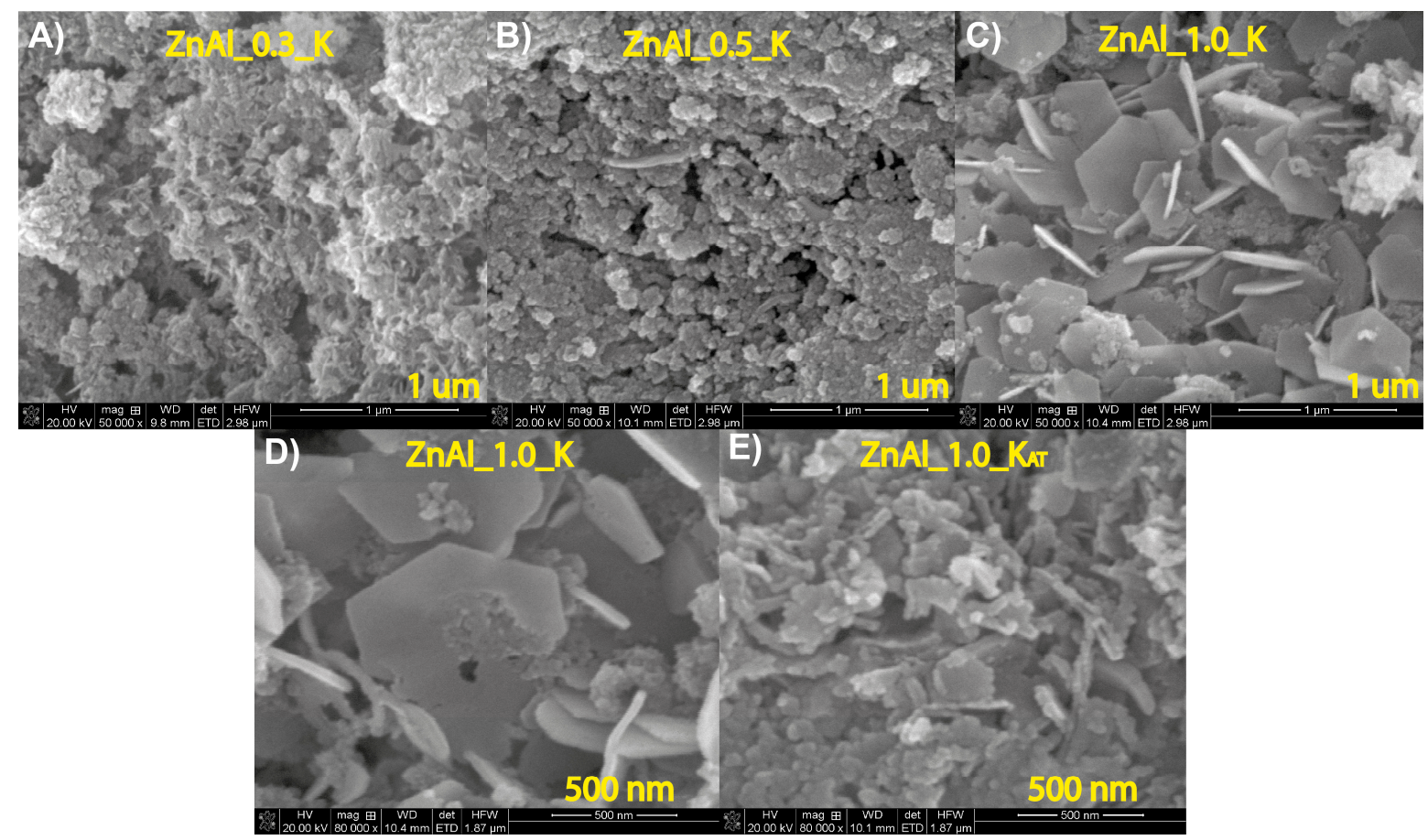

Figure 6. SEM images of the ZnAl_X_K (A) ZnAl_0.3_K, (B) ZnAl_0.5_K, (C) ZnAl_1.0_K, (D) ZnAl_1.0_K and ZnAl_1.0_K $\mathrm{K}_{\mathrm{AT}}$ catalysts (E) ZnAl_1.0_K $\mathrm{K}_{\mathrm{AT}}$.

Analysis of the SEM images proved that sintering of mixed oxides, with concomitant loss of the platelet morphology, occurred during stability tests at $450{ }^{\circ} \mathrm{C}$.

Figure 7 shows TPD-CO ${ }_{2}$ data for the $\mathrm{ZnAl} \_\mathrm{X} \_\mathrm{K}$ catalysts with their deconvoluted three Gaussian peaks. The peak area can be considered as the amount of basic sites of different strengths. Analysis of the TPD- $\mathrm{CO}_{2}$ results obtained for the $\mathrm{ZnAl}$-X_K catalysts showed three ranges of $\mathrm{CO}_{2}$ desorption bands from the mixed oxides surface which demonstrates the presence of alkali centers with various strengths:

(a) weak centers ( $\alpha$ peak); $\mathrm{CO}_{2}$ desorption at $75-180^{\circ} \mathrm{C}$;

(b) medium centers ( $\beta$ peak); $\mathrm{CO}_{2}$ desorption at $180-300{ }^{\circ} \mathrm{C}$;

(c) strong centers ( $\gamma$ peak); $\mathrm{CO}_{2}$ desorption above $300^{\circ} \mathrm{C}$.

Moreover, for the ZnAl_0.5_K catalyst, the shift of bands $(\alpha, \beta, \gamma)$ towards higher maximum peak temperature was observed. Weak basic centers correspond to $\mathrm{O}-\mathrm{H}$ groups on the surface of the catalysts; medium strength sites are associated to the oxygen in $\mathrm{Zn}^{2+}-\mathrm{O}^{2-}, \mathrm{Al}^{3+}-\mathrm{O}^{2-}$ and $\mathrm{K}^{+}-\mathrm{O}^{2-}$ pairs, and strong basic sites correspond to low coordination oxygen atoms [32]. Table S2 shows the contribution of basic sites to $\mathrm{ZnAl} \_\mathrm{X} \_\mathrm{K}$ samples and $\mathrm{T}_{\max }$ desorption. Deconvolution results (see Table $\mathrm{S} 1$ and Figure 7 ) show that medium centers ( $\beta$ peak) are a dominant in all the tested samples.

For ZnAl_0.3_K and ZnAl_1.0_K, similar levels of $\mathrm{CO}_{2}$ desorption are observed which correspond with weak alkali centers $(\alpha)$ and medium centers $(\beta)$. Concomitantly, for ZnAl_1.0_K, the increase in concentration of strong alkali centers $(\gamma)$ on the catalyst surface was observed as compared to ZnAl_0.3_K. For the sample with a stoichiometric spinel molar ratio of $\mathrm{Zn} / \mathrm{Al}$ (ZnAl_0.5_K), the desorption of a larger (compared to the other two samples) amount of $\mathrm{CO}_{2}$ at $180-400{ }^{\circ} \mathrm{C}$ was observed, which indicates that the number of surface active sorption sites is higher for stoichiometric $\mathrm{ZnAl}_{2} \mathrm{O}_{4}$ spinel compared to other studied systems. Moreover, it seems reasonable that the excessive amount of free $\mathrm{ZnO}$ hinders $\mathrm{CO}_{2}$ adsorption on medium alkali centers present on the surface of the ZnAl_1.0_K catalyst. It also seems reasonable to assume that $\mathrm{CO}_{2}$ is less efficiently adsorbed on the zinc-deficient spinel $\mathrm{ZnAl} \_0.3 \_\mathrm{K}$ for the entire range of studied temperatures.

Figure 8A shows kinetic data for the set of $\mathrm{ZnAl}$ _X_K fresh catalysts with different $\mathrm{Zn} / \mathrm{Al}$ molar ratios. The results reveal that the tested catalysts exhibited high catalytic activity in the HT-WGS 
reaction at temperatures up to $400{ }^{\circ} \mathrm{C}$. The activity of the $\mathrm{ZnAl} 0.3 \_\mathrm{K}$ and $\mathrm{ZnAl} 1.0 \_\mathrm{K}$ catalysts containing a defective spinel phase decorated with potassium was high. However, the highest activity was revealed for the sample with a stoichiometric spinel molar ratio of $\mathrm{Zn} / \mathrm{Al}$ (ZnAl_0.5_K). Moreover, the ZnAl_0.5_K catalyst exhibited relatively high activity at a low temperature range of $330-350{ }^{\circ} \mathrm{C}$. The catalytic activity of the ZnAl_X_K catalysts in the HT-WGS reaction is associated with the surface basicity. This confirms well-evidenced observations indicating a correlation between the number of medium basic sites and catalytic activity in the HT-WGS reaction (see TPD-CO $\mathrm{CO}_{2}$ results).

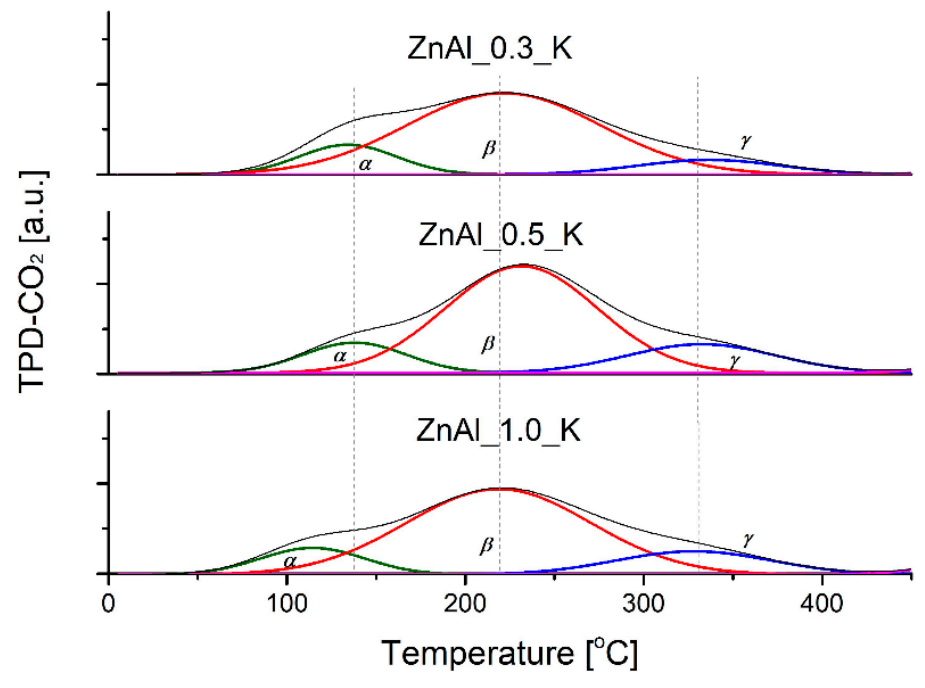

Figure 7. TPD_CO 2 profiles of $\mathrm{ZnAl} \_$__K samples with different $\mathrm{Zn} / \mathrm{Al}$ molar. ratios.
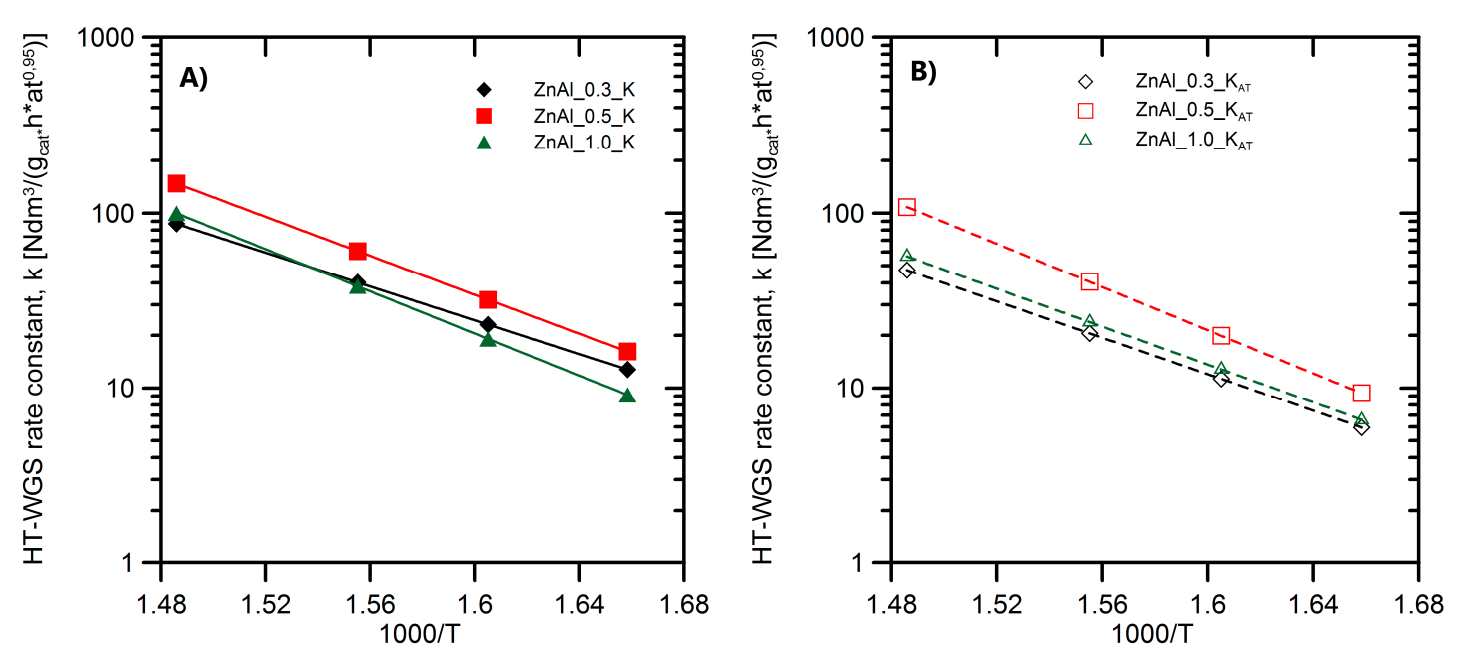

Figure 8. Arrhenius plots for high-temperature water-gas shift (HT-WGS) on ZnAl_X_K (A) and on ZnAl_X_K $\mathrm{K}_{\text {AT }}$ catalysts $(\mathbf{B})$ at $330,350,370$, and $400{ }^{\circ} \mathrm{C}$.

The highest activity of ZnAl_0.5_K in the HT-WGS reaction is caused by the presence of larger (compared to the other two samples) amount of medium basic centers (see Table S2). Moreover, the reasons for lower catalyst activity of ZnAl_1.0_K may be associated with partially disordered structure of $\mathrm{ZnAl}_{2} \mathrm{O}_{4}$ phase in $\mathrm{Zn}-\mathrm{Al}$ mixed oxide catalysts decorated with potassium. According to the FT-IR results (see Figure $4 \mathrm{~A}, \mathrm{~B}$ ), the occurrence of characteristic tetrahedral coordination bands $\left(\mathrm{AlO}_{4}\right)$ indicates a partial inversion of the $\mathrm{ZnAl}_{2} \mathrm{O}_{4}$ spinel structure.

Despite the high activity, the K-decorated $\mathrm{Zn}-\mathrm{Al}$ systems differ in thermal stability depending on the $\mathrm{Zn} / \mathrm{Al}$ molar ratio (Figure 8B). The decrease of activity by ca. 20\% and 40\% for ZnAl_0.5_K and 
ZnAl_1.0_K, respectively, was observed as a result of the samples being overheated in HT-WGS process conditions. This may be caused by recrystallization (see Table 1 ) during the catalyst performance. In spite of recrystallization, the ZnAl_1.0_K catalyst maintained high catalytic activity in the HT-WGS process. The best thermal stability was found for the catalyst with a stoichiometric spinel phase as the dominant one (ZnAl_0.5_K $\mathrm{K}_{\mathrm{AT}}$ ), despite the visible escape of potassium.

Table 2 shows the HT-WGS reaction rate (r) of the ZnAl_X_K and ZnAl_X_K $\mathrm{K}_{\mathrm{AT}}$ catalysts with different $\mathrm{Zn} / \mathrm{Al}$ molar ratios. Additionally, the activity of Fe-based reference HT-WGS catalysts has been presented. The results reveal that, for the tested range of temperatures, the ZnAl_0.5_K catalyst showed higher activity by approx. $20 \%$ as compared to the (Fe-Cr-Cu) reference HT-WGS catalyst. A comparable activity level was observed for ZnAL_1.0_K. A lower activity, as compared to Fe-Cr-Cu, was observed for ZnAL_0.3_K (activity lowered by approx. $10 \%$ at $400{ }^{\circ} \mathrm{C}$ ).

The comparison of data collected in Table 2 also shows the substantial differences of $\mathrm{E}_{\mathrm{a}}$ between the Fe-based reference catalysts and the series of $\mathrm{ZnAl} \_\mathrm{X} \_\mathrm{K}$ and $\mathrm{ZnAl} \mathrm{X} \_\mathrm{K}_{\mathrm{AT}}$ catalysts. As shown in the presented data, the ZnAl_X_K are characteristic of clearly lower Ea values as compared to the $\mathrm{Fe}-\mathrm{Cr}-\mathrm{Cu}(162.2 \pm 1.1)$ applied in the HT-WGS. The presented data for ZnAl_X_K in the kinetic regime are $91.8-115.3 \mathrm{~kJ} / \mathrm{mol}$. For the $\mathrm{ZnAl} \mathrm{X}_{-} \mathrm{K}_{\mathrm{AT}}$ catalysts, slightly lower $\mathrm{E}_{\mathrm{a}}$ values were observed at $99.4-118.74 \mathrm{~kJ} / \mathrm{mol}$.

Table 2. HT-WGS reaction rates with $\mathrm{ZnAl} \_\mathrm{X} \_\mathrm{K}$ and $\mathrm{ZnAl} \_\mathrm{X} \_\mathrm{K}_{\mathrm{AT}}$ catalysts with different $\mathrm{Zn} / \mathrm{Al}$ molar ratios.

\begin{tabular}{|c|c|c|c|c|c|}
\hline Sample & $330^{\circ} \mathrm{C}$ & $350^{\circ} \mathrm{C}$ & $\begin{array}{c}\mathrm{r}\left[\mathrm{Ndm}{ }^{3} \mathrm{CO} \cdot \mathrm{g}^{-1} \cdot \mathrm{h}^{-1}\right] \\
370^{\circ} \mathrm{C}\end{array}$ & $400^{\circ} \mathrm{C}$ & $\mathrm{E}_{\mathrm{a}}[\mathrm{kJ} / \mathrm{mol}]$ \\
\hline ZnAl_0.3_K & 0.40 & 0.52 & 1.08 & 1.87 & $91.8 \pm 0.2$ \\
\hline ZnAl_0.5_K & 0.41 & 0.87 & 1.43 & 2.65 & $106.5 \pm 0.1$ \\
\hline ZnAl_1.0_K & 0.26 & 0.57 & 0.98 & 2.15 & $115.3 \pm 0.3$ \\
\hline ZnAl_0.3_K ${ }_{\mathrm{AT}}$ & 0.14 & 0.39 & 0.56 & 1.00 & $99.4 \pm 0.2$ \\
\hline ZnAl_0.5_K & 0.26 & 0.61 & 0.95 & 2.21 & $118.4 \pm 0.1$ \\
\hline ZnAl_1.0_K & 0.19 & 0.41 & 0.59 & 1.40 & $103.6 \pm 0.1$ \\
\hline $\mathrm{Fe}-\mathrm{Cr}-\mathrm{Cu}{ }^{*}$ & 0.26 & 0.67 & 1.33 & 2.10 & $162.2 \pm 1.1$ \\
\hline
\end{tabular}

\section{Materials and Methods}

\subsection{Materials and Synthesis}

A series of $\mathrm{Zn}-\mathrm{Al}-\mathrm{LDH}$ precursors with different molar ratios of $\mathrm{Zn} / \mathrm{Al}$ were prepared by co-precipitation. $\mathrm{Zn}-\mathrm{Al}-\mathrm{LDH}$ precursors with nominal compositions of $(\mathrm{Zn} / \mathrm{Al})_{\mathrm{mol}}=0.3,0.5$, and 1.0 were prepared by a simultaneous dosing of two streams of $\mathrm{Zn}\left(\mathrm{NO}_{3}\right)_{2} \cdot 6 \mathrm{H}_{2} \mathrm{O}$ (Chempur, Piekary Ślaskie, Poland), $\mathrm{Al}\left(\mathrm{NO}_{3}\right)_{3} \cdot 9 \mathrm{H}_{2} \mathrm{O}$ (99\% purity, Chempur, Piekary Ślaskie, Poland) aqueous solution and $\mathrm{Na}_{2} \mathrm{CO}_{3} / \mathrm{NaOH}$ (99\% purity, Chempur, Piekary Ślaskie, Poland) aqueous solution to the precipitation reactor under vigorous stirring. Synthesis was carried out at a temperature of $75-80^{\circ} \mathrm{C}$ and $\mathrm{pH}$ in the range of 7.5-8. After complete precipitation, the slurry was aged at $80^{\circ} \mathrm{C}$ for $0.5 \mathrm{~h}$ under vigorous stirring. In the next step, the sodium and nitrate ions were thoroughly removed by washing with redistilled water to reach a filtrate conductivity below $150 \mu \mathrm{S} / \mathrm{cm}$, and were then separated, dried, and calcined at $500{ }^{\circ} \mathrm{C}$ for $4 \mathrm{~h}$. The obtained solids were ground to $0.16-0.25 \mathrm{~mm}$ fraction. In the next stage, the materials were subjected to incipient wetness impregnation with an aqueous solution of potassium nitrate (99.0\% purity, Sigma Aldrich, Poznan, Poland) with concentrations selected on the basis of the water absorption of $\mathrm{Zn}-\mathrm{Al}$ oxides, allowing to obtain catalysts with a nominal $\mathrm{K}$ content equal to $3 \mathrm{wt}$. \%. After impregnation, the samples were dried and recalcined at $450{ }^{\circ} \mathrm{C}$ for $2 \mathrm{~h}$. The resulting solids were indicated: $\mathrm{ZnAl} \_\mathrm{X} \_\mathrm{K}$, where $\mathrm{X}$ is the $\mathrm{Zn} / \mathrm{Al}$ molar ratio. 


\subsection{Characterization}

The chemical composition of the samples was determined by the WD XRF method using a Axios mAx spectrometer (Malvern Panalytical, Malvern, UK), equipped with a lamp Rh SST-mAx $4 \mathrm{~kW}$. The specific surface area and total pore volume were determined, using ASAP ${ }^{\circledR} 2050$ Xtended Pressure sorption analyzer (Micromeritics Instrument Co., Norcross, GA, USA), from $\mathrm{N}_{2}$ adsorption and desorption isotherms at a temperature of $-196{ }^{\circ} \mathrm{C}$ for $\mathrm{p} / \mathrm{p} 0 \leq 0.99$, using the BET adsorption model and BJH (Barret-Joyner-Halenda) transformation for mesopore characteristics. The XRD measurements were performed on an Empyrean (Malvern Panalytical, Malvern, UK) system (Bragg-Brentano geometry) equipped with a PIXcel3D detector, using $\mathrm{Cu} \mathrm{K} \alpha$ radiation $(\lambda=1.542 \AA)$ and operating at $40 \mathrm{kV}$ and $40 \mathrm{~mA}$. The crystallite size of the $\mathrm{Zn}-\mathrm{Al}-\mathrm{LDH}$ 's phase was calculated using Scherrer's formula from the diffraction broadening on planes (003), (006), (012), and (015). Fourier-transform infrared spectroscopy (FT-IR) measurements were taken from Nicolet 8700A (Thermo Scientific, USA) equipped with a diamond crystal (Smart Orbit TR diamond ATR). Infrared spectra were obtained in a $4000-400 \mathrm{~cm}^{-1}$ spectral range. A high resolution FEI Quanta3D FEG microscope (Waltham, MA, USA) with an electron beam energy of $20 \mathrm{kV}$ was used in order to analyze the surface morphology by scanning electron microscopy (SEM) using an EDX Octane Elect Plus detector. Analysis of surface composition was carried out for 5 areas $(150 \mu \mathrm{m} \times 150 \mu \mathrm{m})$. The specified surface composition was the average derived from results for five randomly chosen separated sub-areas. The surface basicity of the ZnAl_X_K catalysts was measured by temperature programmed desorption of $\mathrm{CO}_{2}\left(\mathrm{TPD}-\mathrm{CO}_{2}\right)$ using a AutoChem 2950 HP analyzer (Micromeritics Instrument Co., Norcross, GA, USA). Each sample (0.2 g) was pre-treated in a He flow at $500{ }^{\circ} \mathrm{C}$ for $30 \mathrm{~min}\left(10^{\circ} \mathrm{C} / \mathrm{min}\right)$; the samples were then cooled to $200{ }^{\circ} \mathrm{C}$ and $\mathrm{CO}_{2}$ adsorption was performed, and then the samples were cooled to $150^{\circ} \mathrm{C}$. In the next stage, the $\mathrm{CO}_{2}$ stream was replaced with a He purge to remove the physisorbed $\mathrm{CO}_{2}$ and samples were cooled down to $20^{\circ} \mathrm{C}$. Finally, the desorption process was performed at a heating rate of $10^{\circ} \mathrm{C} / \mathrm{min}$ to $500^{\circ} \mathrm{C}$. Surface elemental analyses were performed by X-ray photoelectron spectrometry (multi-chamber analytical system UHV, Prevac, Rogów, Poland) at a base pressure better than $1.0 \times 10^{-8}$ mbar, using a polychromatic Al K X-ray source $(1486.7 \mathrm{eV})$.

\subsection{Methods}

The catalysts' activity and thermal stability in the HT-WGS reaction were carried out in kinetic regime using a 4-channel differential reactor (at a conversion degree below 0.2). HT-WGS measurements were performed under the following conditions: catalyst grain size $(\mathrm{mm}), 0.16-0.25$; pressure (MPa), 2.5; temperature $\left({ }^{\circ} \mathrm{C}\right), 330-400$; gas flow $\left(\mathrm{Ndm}^{3} / \mathrm{h}\right), 60$; dry gas composition (\% vol.); $\mathrm{CO} / \mathrm{CO}_{2} / \mathrm{H}_{2}=3.0 / 10.0 / 87.0 ; \mathrm{H}_{2} \mathrm{O} /$ gas molar ratio $=1$.

The HT-WGS reaction rate at the kinetics regime was calculated based on a mass balance of the reactor:

$$
\mathrm{r}=0.01 \cdot \mathrm{V} \cdot \Delta \mathrm{C}_{\mathrm{CO}} \cdot \mathrm{m}_{\mathrm{cat}}^{-1}
$$

where:

$\mathrm{r}$-measured HT-WGS reaction rate in the kinetics regime $\left(\mathrm{Ndm}^{3} \mathrm{CO} \cdot \mathrm{g}^{-1} \cdot \mathrm{h}^{-1}\right)$,

V—dry gas flow $\left[\mathrm{Ndm}^{3} \cdot \mathrm{h}^{-1}\right]$,

$\Delta \mathrm{C}_{\mathrm{CO}}$ - the difference between inlet and outlet $\mathrm{CO}$ content in a dry gas [vol. \%],

$\mathrm{m}_{\text {cat }}$ - - weight of the catalyst sample.

The HT-WGS reaction rate constant was calculated from the equation:

$$
\mathrm{r}=\mathrm{k} \cdot \mathrm{pCO}^{1.04} \cdot \mathrm{pCO}_{2}^{-0.25} \cdot \mathrm{pH}_{2} \mathrm{O}^{0.16} \cdot \mathrm{pH}_{2} \mathrm{O} \cdot(1-\beta)
$$

where:

$\mathrm{r}$-HT-WGS reaction rate $\left[\mathrm{Ndm}{ }^{3} \mathrm{CO} /\left(\mathrm{g}_{\text {cat }} \cdot \mathrm{h}\right)\right]$, 
k-HT-WGS rate constant $\left[\mathrm{Ndm}{ }^{3} \mathrm{CO} /\left(\mathrm{g}_{\text {cat }} \cdot h \cdot a t^{0.95}\right)\right]$,

$\mathrm{pCO}, \mathrm{pCO}_{2}, \mathrm{pH}_{2}, \mathrm{pH}_{2} \mathrm{O}$ - partial pressure of $\mathrm{CO}, \mathrm{CO}_{2}, \mathrm{H}_{2}, \mathrm{H}_{2} \mathrm{O}$ [ata],

$\beta=\mathrm{pCO}_{2} \cdot \mathrm{pH}_{2} \cdot \mathrm{K}_{\mathrm{p}}{ }^{-1} \cdot \mathrm{pCO}^{-1} \cdot \mathrm{pH}_{2} \mathrm{O}^{-1}$-approach to equilibrium,

$\mathrm{K}_{\mathrm{p}}-\mathrm{WGS}$ equilibrium constant.

The catalytic effect's durability was evaluated on the basis of activity changes as a result of overheating the catalysts at $450{ }^{\circ} \mathrm{C}$ over $24 \mathrm{~h}$ in a stream of process gas. The ZnAl_X_K catalysts, after long-term stability tests, were indicated as $\mathrm{ZnAl} \mathrm{X}_{-} \mathrm{K}_{\mathrm{AT}}$, where $\mathrm{X}$ is the $\mathrm{Zn} / \mathrm{Al}$ molar ratio.

\section{Conclusions}

Mixed oxide catalysts $\left(\mathrm{ZnO} / \mathrm{ZnAl}_{2} \mathrm{O}_{4}\right)$ derived from $\mathrm{LDH}$ precursors and K-decorated showed high specific surface areas. Increasing the $\mathrm{Zn} / \mathrm{Al}$ molar ratio resulted in decreases in the specific surface area and total pore volume of catalysts. The amount and strength of surface basic sites on ex-ZnAl-LDH decorated with potassium depended on the $(\mathrm{Zn} / \mathrm{Al})_{\text {mol }}$ ratio. The correlation of activity results and TPD- $\mathrm{CO}_{2}$ data show that medium basic sites enhance HT-WGS reaction.

The catalytic activity of ZnAl_X_K in the HT-WGS reaction was relatively high and depended on the $\mathrm{Zn} / \mathrm{Al}$ molar ratio. The highest activity was observed for the catalyst with a stoichiometric spinel molar ratio of $\mathrm{Zn} / \mathrm{Al}$ (ZnAl_0.5_K). The catalyst containing a zinc-deficient spinel phase decorated with potassium ( $\mathrm{ZnAl} \_0.3 \_\mathrm{K}$ ) and the catalyst with partial inversion of the $\mathrm{ZnAl}_{2} \mathrm{O}_{4}$ spinel phase in $\mathrm{Zn}-\mathrm{Al}$ mixed oxide decorated with potassium (ZnAl_1.0_K) showed lower catalytic activity in HT-WGS process conditions.

Sintering of $\mathrm{ZnO}-\mathrm{ZnAl}{ }_{2} \mathrm{O}_{4}$ mixed oxides, with a concomitant loss of platelet morphology, occurred even during the preparation of calcinations step $\left(500^{\circ} \mathrm{C}\right)$. Nevertheless, in spite of recrystallization as a result of overheating, the ZnAl_1.0_K catalyst maintained high catalytic activity in the HT-WGS process. The catalyst with a stoichiometric spinel molar ratio of $\mathrm{Zn} / \mathrm{Al}$ (ZnAl_0.5_K showed a higher level of activity by about $20 \%$ compared to the $\mathrm{Fe}-\mathrm{Cr}-\mathrm{Cu}$ catalyst.

Supplementary Materials: The following are available online at http://www.mdpi.com/2073-4344/10/9/1094/s1: Table S1: The comparison of the physicochemical properties and lattice parameters of ZnAl_X_LDHs; Table S2: Contribution of basic sites for ZnAl_X_K catalysts. Peak area ratio is defined as the ratio of the sum of $\alpha, \beta$ and $\delta$ peak area of $\mathrm{ZnAl} \_\mathrm{X} \_\mathrm{K}$ catalysts to $\mathrm{ZnAl}$.0.5_K catalyst; Figure S1: Pore size distribution of ZnAl_X_K and ZnAl_X_K

Author Contributions: K.A.-J., methodology, supervision and writing—original draft; P.K., writing-review and editing; K.M., investigation.; W.P., investigation.; R.B., investigation. All authors have read and agreed to the published version of the manuscript.

Funding: The research was supported by the National Science Centre, Poland, within the SONATA program, under grant no. 2017/26/D/ST5/01211.

Acknowledgments: The authors thank A. Nowicka for her SEM-EDS analysis. The authors thank W. Sofinska-Chmiel for her FT-IR analysis. The research was carried out with equipment purchased thanks to the financial support of the European Regional Development Fund in the framework of the Polish Innovation Economy Operational Program (contract no. POIG.02.01.00-06024/09-Centre of Functional Nanomaterials).

Conflicts of Interest: The authors declare no conflict of interest.

\section{References}

1. Aasberg-Petersen, K.; Dybkjær, I.; Ovesen, C.V.; Schjødt, N.C.; Sehested, J.; Thomsen, S.G. Natural gas to synthesis gas-Catalysts and catalytic processes. J. Nat. Gas Sci. Eng. 2011, 3, 423-459. [CrossRef]

2. Saeidi, S.; Fazlollahi, F.; Najari, S.; Iranshahi, D.; Klemeš, J.J.; Baxter, L.L.; Fazollahi, F. Hydrogen production: Perspectives, separation with special emphasis on kinetics of WGS reaction: A state of the art review. J. Ind. Eng. Chem. 2017, 49, 1-25. [CrossRef]

3. Ishaq, H.; Dincer, I. Analysis and optimization for energy, cost and carbon emission of a solar driven steam-autothermal hybrid methane reforming for hydrogen, ammonia and power production. J. Clean. Prod. 2019, 234, 242-257. [CrossRef]

4. Lloyd, L. Handbook of Industrial Catalysts; Springer Science and Business Media LLC: Berlin, Germany, 2011. 
5. Ratnasamy, C.; Wagner, J.P. Water Gas Shift Catalysis. Catal. Rev. 2009, 51, 325-440. [CrossRef]

6. Antoniak-Jurak, K.; Kowalik, P.; Próchniak, W.; Raróg-Pilecka, W.; Kuśtrowski, P.; Ryczkowski, J. Sour gas shift process over sulfided Co-Mo-K catalysts supported on carbon material-Support characterization and catalytic activity of catalysts. Fuel Process. Technol. 2015, 138, 305-313. [CrossRef]

7. Zhu, M.; Wachs, I.E. Iron-Based Catalysts for the High-Temperature Water-Gas Shift (HT-WGS) Reaction: A Review. ACS Catal. 2016, 6, 722-732. [CrossRef]

8. Lee, J.Y.; Lee, D.-W.; Lee, K.-Y.; Wang, Y. Cr-free Fe-based metal oxide catalysts for high temperature water gas shift reaction of fuel processor using LPG. Catal. Today 2009, 146, 260-264. [CrossRef]

9. Sourav, S.; Wachs, I.E. Cr-Free, Cu Promoted Fe Oxide-Based Catalysts for High-Temperature Water-Gas Shift (HT-WGS) Reaction. Catalysts 2020, 10, 305. [CrossRef]

10. Jha, A.; Jeong, D.-W.; Lee, Y.-L.; Jang, W.-J.; Shim, J.-O.; Jeon, K.-W.; Rode, C.V.; Roh, H.-S. Chromium free high temperature water-gas shift catalyst for the production of hydrogen from waste derived synthesis gas. Appl. Catal. A Gen. 2016, 522, 21-31. [CrossRef]

11. De Araújo, G.C.; Rangel, M. An environmental friendly dopant for the high-temperature shift catalysts. Catal. Today 2000, 62, 201-207. [CrossRef]

12. Kowalik, P.; Bicki, R.; Antoniak-Jurak, K.; Prochniak, W.; Michalska, K.; Mrozek, A. Quaternary Fe-Cu-Cr-Al HT-WGS catalysts-effect of Al substitution on the efficiency at steam-lean process gas. Eur. J. Inorg. Chem. 2020. [CrossRef]

13. Damma, D.; Smirniotis, P.G. FeCeOx Supported Ni, Sn Catalysts for the High-Temperature Water-Gas Shift Reaction. Catalysts 2020, 10, 639. [CrossRef]

14. Ertl, G.; Knözinger, H.; Weitkam, J. Preparation of Solid Catalysts; John Wiley \& Sons: Hoboken, NJ, USA, 2012.

15. Twigg, M.V.; Spencer, M.S. Deactivation of supported copper metal catalysts for hydrogenation reactions. Appl. Catal. A Gen. 2001, 212, 161-174. [CrossRef]

16. Kowalik, P.; Antoniak-Jurak, K.; Próchniak, W.; Wiercioch, P.; Konkol, M.; Bicki, R.; Michalska, K.; Walczak, M. The Evaluation of Synthesis Route Impact on Structure, Morphology and LT-WGS Activity of Cu/ZnO/Al $\mathrm{O}_{3}$ catalysts. Catal. Lett. 2017, 147, 1422-1433. [CrossRef]

17. Kowalik, P.; Antoniak-Jurak, K.; Bicki, R.; Próchniak, W.; Wiercioch, P.; Michalska, K. The alcohol-modified $\mathrm{CuZnAl}$ hydroxycarbonate synthesis as a convenient preparation route of high activity $\mathrm{Cu} / \mathrm{ZnO} / \mathrm{Al}_{2} \mathrm{O}_{3}$ catalysts for WGS. Int. J. Hydrog. Energy 2019, 44, 913-922. [CrossRef]

18. Sun, Y.; Zhou, Y.; Wang, Z.; Ye, X. Structural and morphological transformations of Zn-Al layered double hydroxides through hydrothermal treatment. Appl. Surf. Sci. 2009, 255, 6372-6377. [CrossRef]

19. Xu, M.; Wei, M. Layered Double Hydroxide-Based Catalysts: Recent Advances in Preparation, Structure, and Applications. Adv. Funct. Mater. 2018, 28, 1802943. [CrossRef]

20. Bukhtiyarova, M.V. A review on effect of synthesis conditions on the formation of layered double hydroxides. J. Solid State Chem. 2019, 269, 494-506. [CrossRef]

21. He, J.; Wei, M.; Li, B.; Kang, Y.; Evans, D.G.; Duan, X. Preparation of Layered Double Hydroxides. In Layered Double Hydroxides; Springer Science and Business Media: Berlin, Germany, 2006.

22. Lee, M.S.; Lee, J.Y.; Lee, D.-W.; Moon, D.J.; Lee, K.-Y. The effect of Zn addition into NiFe2O4 catalyst for high-temperature shift reaction of natural gas reformate assuming no external steam addition. Int. J. Hydrog. Energy 2012, 37, 11218-11226. [CrossRef]

23. Lee, J.Y.; Lee, D.-W.; Lee, M.S.; Lee, K.-Y. Cs-promoted Ni/Fe catalyst as a Cr-free, high temperature shift catalyst for steam methane reformate without additional supply of steam. Catal. Commun. 2011, 15, 37-40. [CrossRef]

24. Tanaka, Y.; Ukata, T.; Kikuchi, R.; Takeguchi, T.; Sasaki, K.; Eguchi, K. Water gas shift reaction for the reformed fuels over $\mathrm{Cu} / \mathrm{MnO}$ catalysts prepared via spinel-type oxide. J. Catal. 2003, 215, 271-278. [CrossRef]

25. Park, S.-W.; Joo, O.-S.; Jung, K.-H.; Kim, H.; Han, S.-H. Development of $\mathrm{ZnO} / \mathrm{Al}_{2} \mathrm{O}_{3}$ catalyst for reverse-water gas shift reaction of CAMERE (carbon dioxide hydrogenation to form methanol via a reverse-water-gas-shift reaction) process. Appl. Catal. A 2001, 211, 81-90. [CrossRef]

26. Joo, O.S.; Jung, K.D. Stability of $\mathrm{ZnAl}_{2} \mathrm{O}_{4}$ Catalyst for Reverse-Water-Gas-Shift Reaction (RWGSR). Bull Korean Chem. Soc. 2003, 24, 86-90.

27. Bieniasz, W.; Trębala, M.; Sojka, Z.; Kotarba, A. Irreversible deactivation of styrene catalyst due to potassium loss-Development of antidote via mechanism pinning. Catal. Today 2010, 154, 224-228. [CrossRef] 
28. Tajuddin, N.A.; Manayil, J.C.; Isaacs, M.A.; Parlett, C.M.A.; Lee, A.F.; Wilson, K. Alkali-Free Zn-Al Layered Double Hydroxide Catalysts for Triglyceride Transesterification. Catalysts 2018, 8, 667. [CrossRef]

29. Ni, J.; Xue, J.; Shen, J.; He, G.; He, G. Fabrication of ZnAl mixed metal-oxides/RGO nanohybrid composites with enhanced photocatalytic activity under visible light. Appl. Surf. Sci. 2018, 441, 599-606. [CrossRef]

30. Kowalik, P.; Konkol, M.; Antoniak-Jurak, K.; Próchniak, W.; Wiercioch, P.; Rawski, M.; Borowiecki, T. Structure and morphology transformation of $\mathrm{ZnO}$ by carbonation and thermal treatment. Mater. Res. Bull. 2015, 65, 149-156. [CrossRef]

31. Sing, K.S.W.; Everett, D.H.; Haul, R.A.W.; Moscou, L.; Pierotti, R.A.; Rouquerol, J.; Siemieniewska, T. Reporting physisorption data for gas/solid systems with special reference to the determination of surface area and porosity. Pure Appl. Chem. 1985, 57, 603-619. [CrossRef]

32. Tzompantzi, F.; Carrera, Y.; Morales-Mendoza, G.; Valverde-Aguilar, G.; Mantilla, A. $\mathrm{ZnO}-\mathrm{Al}_{2} \mathrm{O}_{3}-\mathrm{La}_{2} \mathrm{O}_{3}$ layered double hydroxides as catalysts precursors for the esterification of oleic acid fatty grass at low temperature. Catal. Today 2013, 212, 164-168. [CrossRef]

(C) 2020 by the authors. Licensee MDPI, Basel, Switzerland. This article is an open access article distributed under the terms and conditions of the Creative Commons Attribution (CC BY) license (http://creativecommons.org/licenses/by/4.0/). 